\title{
ADVANCED POWER GRID ANALYSIS IN METALLURGICAL PLANTS WITH USAGE OF DISCRETE FOURIER TRANSFORM
}

\author{
Ondřej GRYCZ1 ${ }^{1}$, Vít PASKER ${ }^{2}$, Robert HLAVICA ${ }^{3}$, Hana ŠPAČKOVÁ4 ${ }^{4}$ Martin MENŠíK ${ }^{5}$ \\ VSB - Technical University of Ostrava, Ostrava, Czech Republic, EU \\ 1ondrej.grycz@vsb.cz, ${ }^{2}$ vit.pasker@vsb.cz, ${ }^{3}$ robert.hlavica@vsb.cz,.4hana.spackova@vsb.cz, \\ 5martin.mensik@vsb.cz
}

https://doi.org/10.37904/metal.2019.774

\begin{abstract}
The article deals with quality analysis of power grids especially in metallurgical industry when using large engines, arc furnace, induction heating and so on. Nowadays, these non-linear loads which are connected to power grids cause heavy disturbances, which can cause big problems like damage or even destruction of machines or devices connected near the point, where disturbances occur. Identification of disturbances is then very important for elimination of these problems. The article describe progress in detecting mentioned anomalies namely application of discrete Fourier transform which is suitable tool for measuring the anomalies. Discrete Fourier transform can be implemented in modern type microprocessors so there is a possibility to measure and evaluate measured results quickly and efficiently. Based on measured values the power grid in the factory can be analyzed and the improvement can be proposed.
\end{abstract}

Keywords: Metallurgy, power grid, microprocessor, discrete Fourier transform

\section{INTRODUCTION}

Metallurgical plants are solving very big problems with power grid inside it nowadays. Whole cities around of metallurgical plants are touched by this problems. This problems in power grid brings another problems with electrical machines, equipment and devices like shorter life time or even destroying of this ones. Correct identification of problem is very necessary so it is very important precisely measure condition of power grid. Elimination of problems in power grids is much easier when the correct values are measured and counted.

\section{PROBLEM ANALYSIS}

In ordinary power grid voltage sinusoidal shape with frequency $50 \mathrm{~Hz}$ can be founded. There is only this fundamental frequency in ideal condition. Disturbation of power grid is caused by nonlinear loads like switching power supplies for example. This devices generating higher frequencies which are added on fundamental $50 \mathrm{~Hz}$ sinusoidal voltage. This frequencies are multiple of fundamental $50 \mathrm{~Hz}($ e.g. $100 \mathrm{~Hz}, 150 \mathrm{~Hz}, \ldots)$ and they are called harmonics. Ideal sinusoidal voltage with $50 \mathrm{~Hz}$ frequency is shown in Figure 1. Disturbed real sinusoid which is in real power grid is shown in Figure 2. [1,2]

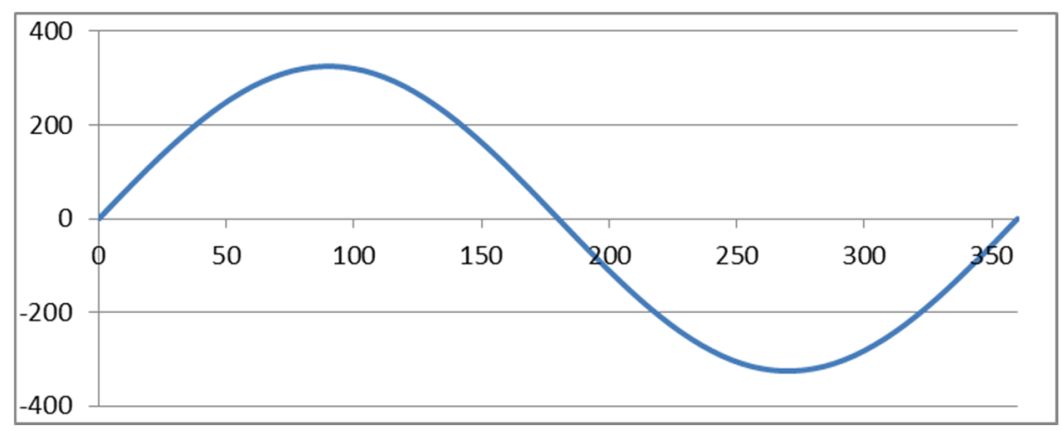

Figure 1 Ideal sinusoid 


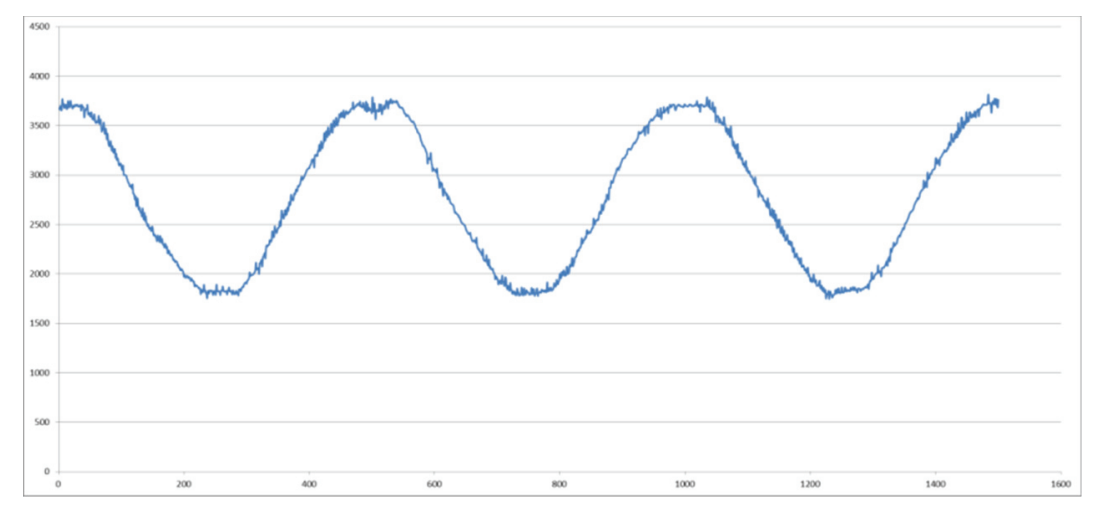

Figure 2 Measured distorted sinusoid

Higher harmonics are defined in theory of Fourier transform which says every harmonic function is the sum of sinuses and cosines with different frequencies and amplitudes. The Fourier transform deal with count of these harmonics and their amplitude. Result of Fourier transform is spectrum of signal. There are individual frequencies on the horizontal axe and amplitudes of these harmonics are on the vertical axe. Fourier transform converts signal from time domain to frequency domain.

Total harmonic distortion shortly THD gives ratio of energies from harmonics and energy from fundamental frequency $50 \mathrm{~Hz}$. THD is based on decomposition periodic signal on individual harmonics by Fourier transform. THD is mostly defined as share of individual energies as in equation (1). [3,4,5]

$T H D=\frac{\sum_{2}^{n} P_{n}}{P_{1}} * 100$

where:

$P_{n}$ - electric power of higher frequencies (W)

$P_{1}$ - electric power of fundamental $50 \mathrm{~Hz}(W)$

$n$ - count of harmonic frequencies

Harmonic distortion of voltage and current is computed by equations (2) and (3).

$T H D=\frac{\sqrt{\sum_{2}^{n} U_{n}^{2}}}{U_{1}} * 100$

where:

$$
\begin{aligned}
& U_{n} \text { - voltage of harmonic }(\mathrm{V}) \\
& U_{1} \text { - voltage of fundamental } 50 \mathrm{~Hz}(\mathrm{~V})
\end{aligned}
$$

$T H D=\frac{\sqrt{\sum_{2}^{n} I_{n}{ }^{2}}}{I_{1}} * 100$

where:

$$
\begin{aligned}
& I_{n} \text { - current of harmonic (A) } \\
& I_{1} \text { - current of fundamental } 50 \mathrm{~Hz}(\mathrm{~A})
\end{aligned}
$$

Power grid quality not only by THD is defined in standart EN 50160. Distorted voltage or current causes very big problems in power grids for several reasons. THD increase temperature of transformers and they have to be over-dimensioned for security reasons. Ability to transfer distorted current of transformers is called $\mathrm{K}$ factor. 
If the transformer is not designed to transfer distorted current it burns. Conductors are overloaded by distorted current so they have to be over-dimensioned too. If the THD is too high it can cause damage or even destruction of electrical appliances. In case of 3 phase power grid the $3^{\text {rd }}$ multiples are added on neutral conductor and high frequency current flow by this neutral conductor. This phenomenon is called triplen harmonics and it appear because $3^{\text {rd }}$ multiples are in phase. The other multiples have phase shift between themselves. If THD appear in power grid it is necessary dimension grid on harmonics components. Sum of transferred power is vector computed by Figure 3. [6,7,8]

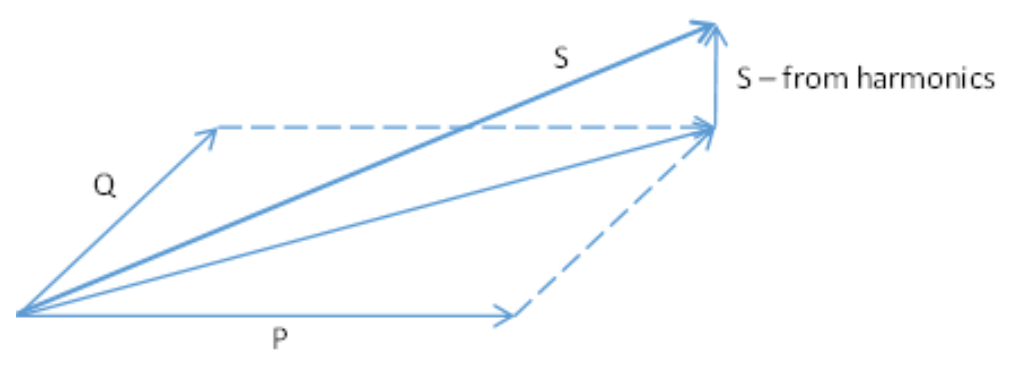

Figure 3 Vector sum of powers

\section{SOLUTION}

For correct counting of THD there is necessary measure each harmonic frequency in power grid. Device for this type measuring has to be very fast and very precise but they are very expensive. In this paper was developed system for measuring harmonic frequencies based on 32 bit microprocessor from manufacturer ST Microelectronics. This microprocessor is cheap and efficient for computations discrete Fourier transform and its algorithm. Presence of analog peripheries like analog operational amplifiers or AD convertors in this microprocessor secure small dimensions and increase of accuracy. The microprocessor is able compute and compare individual harmonic components from shape of the waveform by algorithm of discrete Fourier transform. It is possible rate the degree of distortion and quality of power grid in metallurgical factory.

After ADC measuring and conversion it is necessary calculate frequency spectrum. This calculation is executed by discrete Fourier transform algorithm. Equation (1), (2) and (3) are implemented into microprocessor.

$X_{R e i}=X_{R e(i-1)}+$ sample $*\left(\cos \left(\frac{k * i * 2 \pi}{\text { count samples }}\right)\right)$

$X_{\operatorname{Im} i}=X_{\operatorname{Im}(i-1)}+$ sample $*\left(\sin \left(\frac{k * i * 2 \pi}{\text { count samples }}\right)\right)$

$d f t=\sqrt{X_{R e}^{2}+X_{I m}^{2}}$

where:

$X_{R e}$ - real part dicrete Fourier transform

$X_{I m}$ - imaginary part dicrete Fourier transform

sample - result of $A D$ converted sample

$k$ - number of harmonic component

$i$ - iteration of counting

count samples - amount of all samples from AD converting

$d f t$ - result of 1 harmonic component of discrete Fourier transform 
These equations calculate one component of frequency spectrum from one measured sample from $A D$ convertor. For complete spectrum it is necessary execute these equations in the loop. Count of loops depends on maximal harmonics frequency which is required. This dft algorithm in equation above is debugged for 32bit microprocessor for decrease counting time as much as possible by using floating point unit in used microprocessor.

Microprocessor after calculation send results to the PC or any other system by serial interface. From these data main system can draw all frequency spectrum of measured signal or some part which is required as it is shown on Figure 4. This frequency spectrum is very important for identification problem in power grid and it is very strong tool for finding source of problem in power grid.

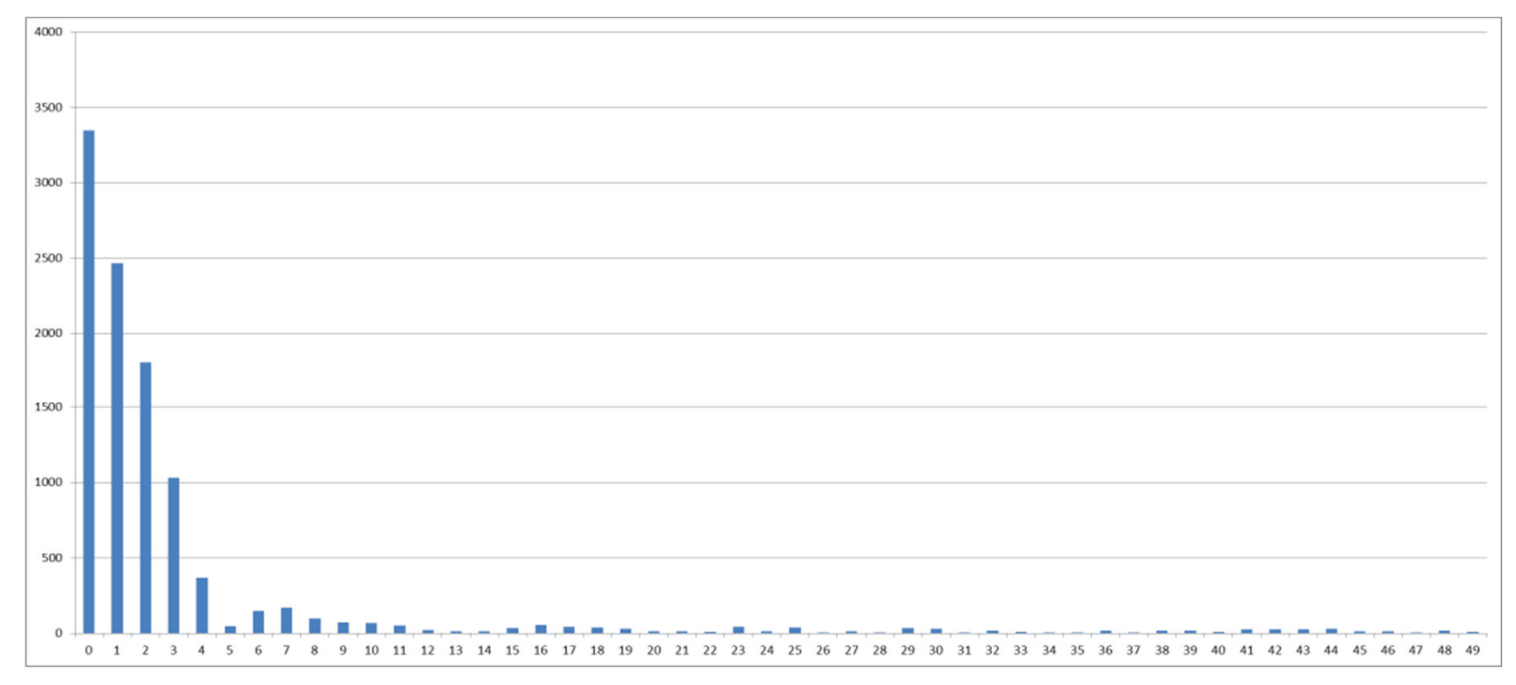

Figure 4 Frequency spectrum of measured signal

\section{CONCLUSION}

In this paper was described implementation of discrete Fourier transform in the modern 32 bit microprocessor. This algorithm of discrete Fourier transform is used for measuring of disturbances in power grid in metallurgical plant. System compute ratio of individual harmonic components which cause disturbances in power grid from measured waveforms. This system was developed on demand from unnamed metallurgical factory near Katowice where first measuring was done. Thanks to computing power of used 32 bit microprocessor and optimization of discrete Fourier transform for this type of microprocessor the measuring system is able precisely and very quickly compute every harmonic component through all required frequency spectrum. This is very important and necessary step to identification and then elimination source of these disturbances.

\section{ACKNOWLEDGEMENTS}

The work was supported by the specific university research of Ministry of Education, Youth and Sports of the Czech Republic No. SP2019/17 and SP2019/62.

\section{REFERENCES}

[1] COSTA, A., GEORGIDIS, D., NG, TS., SIM, M. An optimization model for power grid fortification to maximize attack immunity. INTERNATIONAL JOURNAL OF ELECTRICAL POWER \& ENERGY SYSTEMS, 2018, vol. 99, pp. 596-605. 
[2] SATPATHI, K., YEAP, YM., UKIL, A., GEDDADA, N. Short-Time Fourier Transform Based Transient Analysis of VSC Interfaced Point-to-Point DC System. IEEE TRANSACTIONS ON INDUSTRIAL ELECTRONICS, 2018, vol. 65 , iss. 5 , pp. 4080-4091.

[3] LIU, YK., XU, X. Industry 4.0 and Cloud Manufacturing: A Comparative Analysis. Journal of manufacturing science and engineering-transactions of the asme. 2017, vol. 139, no. 034701, pp.10-20.

[4] SVEC, P., FRISCHEROVA, L., DAVID, J. Usage of clustering methods for sequence plan optimization in steel production. Metalurgija, 2016, vol. 55, pp. 485-488.

[5] KREJCAR, O. and R. FRISCHER. Real Time Voltage and Current Phase Shift Analyzer for Power Saving Applications. Sensors. 2012, vol. 12, no 8, pp. 11391-11405.

[6] SEIDL, D., KOŠTIAL, P., JANČíKOVÁ, Z., RUŽIAK, I., RUSNÁKOVÁ, S., FARKAŠOVÁ, M. Modal analysis Measurements versus FEM and artificial neural networks simulation. Communications in Computer and Information Science, 2011, vol. 188, Issue PART 1, pp. 170-175.

[7] KOIWA, K., LIU, KZ., TAMURA, J., Analysis and Design of Filters for the Energy Storage System: Optimal Tradeoff Between Frequency Guarantee and Energy Capacity/Power Rating. IEEE TRANSACTIONS ON INDUSTRIAL ELECTRONICS, 2018, vol. 65, pp. 6560-6570.

[8] DAVID, J., POLLAK, M., TUHY, T., PRAZAKOVA, V. Modern communication technologies usage for controlling metallurgical processes. In METAL 2014: 23rd International Conference on Metallurgy and Materials. Ostrava: TANGER, 2014, pp. 1678-1683. 